\title{
The limit state of non-hinged arch with a cross-section in the form of an idealized I- beam
}

\author{
Mykola Soroka $^{\# 1}$ \\ \# Department of structural mechanics, \\ Odesa State Academy of Civil Engineering and Architecture, Odesa, Ukraine \\ ${ }^{1}$ soroka@ogasa.org.ua
}

\begin{abstract}
Using the direct method for the calculation of trussed systems taking into account the bending moment and the longitudinal force with a simple method of load application was analysed. The simplicity and efficiency of the direct calculation method for determining the parameters of the limit load is shown. According to the developed methodology, a calculation program was compiled, which allows determining the maximum load, the sequence of transition of the system sections to the limit state. The resulting method allows to obtain the values of efforts at all stages of the calculation, as well as at the time of exhaustion of the carrying capacity. To control the correctness of the results obtained, an analytical calculation of a circular hinged arch loaded with a vertical uniformly distributed load was performed. The good convergence of the results obtained using the calculation program and the analytical method are shown. The comparison of the limit load and the efforts in the limiting state, obtained taking into account the longitudinal force and without the longitudinal force was made.
\end{abstract}

Keyword - Limit load, Accounting for longitudinal force, Non-hinged arch, Calculation program

\section{INTRODUCTION}

The limit state of structures is such a condition in which their subsequent operation becomes impossible. In this paper we consider the case when the limit state is caused by the loss of the material resistance to the external load. The limit condition is also called the loss of the bearing capacity of the structure. The purpose of the calculation is to determine the limit load, its greatest load at which equilibrium is satisfied, or the smallest load at which the system is converted into a mechanism.

\section{PROBLEM FORMULATION}

The calculation of the limit state was first proposed by Galileo, but the level of science at that time did not allow for practical results. The problem of calculating the limit load was considered in the works of $\mathrm{O}$. Hvozdieva [1], A. Rzhanitsyna [2], A. Pikovskoho [3], A. Chyrasa [4], and other researchers. The main attention was paid to the study of the limit state taking into account only the bending moments. Some results of the research of the longitudinal force effect on the parameter of the limit load are given in [4] - [6]. But the universal method of calculating trussed systems, where along with the bending moment longitudinal forces are taken into account, has not been developed yet.

\section{A. Aim of paper}

The aim of the work is to developa methodology and program for calculating the parameter of the limit load for flat trussed systems with a simple load and to justify the need to take into account in the calculations the longitudinal force.

\section{B. Materials and methods}

The calculation of the load-bearing capacity of a flat trussed system is performed under the following assumptions.

1. Consider a flat trussed system, which is in the condition of a simple static load.

2. The cross-section of the trussed system enters a limiting state under the influence of a combination of bending moment and longitudinal force, the influence of shear forces is not taken into account.

3. Till the appearance of the limiting state, the section operates according to Hooke's law.

4. The material is considered with the same values of yield strength under tension and compression.

5. Plastic deformations occurred in the section, at the point of application of the limit combinations consisting of a bending moment and a longitudinal force.

6. Mutual rotation and linear movement along the axis of the rod sections, adjacent to the area of plasticity, grow indefinitely without increasing bending moment and longitudinal force.

7. Under the influence of limit load, the trussed system, or its parts, do not lose stability. 
To determine the limit load, we used the direct method of calculation described in [7] - [9] for determining the limit load without considering the longitudinal force. The algorithm of this method, taking into account the moment and longitudinal force in a short form can be described:

1. For all rods of the system we build areas of bearing capacity of sections.

2. We apply a load with a parameter $\mathrm{F}=1$ to the trussed system, from which we determine the values of bending moments $M_{1 i_{-}}$and longitudinal forces $N_{1 i}$ in all design sections of the system.

3. For each section, we calculate the value of the destructive load $M_{p i}$ and $N_{p i}$, (affect the limit state), as well as the value of the corresponding load

$$
F_{i}=\frac{M_{p i}}{M_{1 i}} .
$$

4. Determine the cross section, for which the transition to the limit state you need to attach the smallest value of the load $F_{1}=\min \left(F_{i}\right)$. We calculate the value of the forces in all sections from the load by multiplying the efforts from the unit load on $F_{1}$ :

$$
M_{s}=F_{1} M_{1} ; \quad N_{s}=F_{1} N_{1} .
$$

5. In the section where the ultimate state occurs, we establish the hinge and assume axial stiffness $E A=0$. If the system has turned into a mechanism, we should go to the step 10 .

6. To the modified trussed system, we apply a load with a parameter $\Delta F=1$ from which we determine the values of bending moments $M_{1 i}$ and longitudinal forces $N_{1 i}$ in all calculated sections.

7. For each section, taking into account the efforts received at the previous stage $M_{s}$ and $N_{s}$, we calculate the value of the destructive forces $M_{p i}$ and $N_{p i}$ which transfer the section into the ultimating state, as well as the value of the increase in the corresponding load $\Delta F_{i}=\left(M_{p i}-M_{s i}\right) / M_{1 i}$.

8. Determine the cross section in which transfer to the limit state is sufficiently the smallest value of the increase in load. Calculate the value of force in all sections.

9. We should go to the step 5 .

$$
M_{s}=M_{s}+\Delta F \cdot M_{1} ; \quad N_{s}=N_{s}+\Delta F \cdot N_{1} .
$$

10. Determine the parameter of limit load

$$
F_{0}=F_{1}+\sum \Delta F .
$$

\section{RESEARCH RESULTS}

In contrast to the computation which takes into account only the bending moments, in consideration of the longitudinal force calculation requires knowledge of cross-sectional shapes of rods. In this paper, we consider the cross-sectional shape in the form of an idealized I-beam (Fig. 1a). For such a cross section, the limit moment and the limit longitudinal force are calculated by the formulas [2]

where $\sigma_{y}$ - yield tensile of material.

$$
M_{0}=\sigma_{y} b t h ; \quad N_{0}=2 \sigma_{y} b t,
$$

The condition of the yield tensile of the section is described by the expression

$$
\left|M_{p}\right|+0.5 h\left|N_{p}\right|=M_{0},
$$

where $M_{p}$ and $N_{p}$-destructive moment and longitudinal force for this section.

The boundary of the carrying capacity of the section is a rhombus (Fig. 1b). If $M$ and $N$, for a given section, they are inside the region of the carrying capacity, the section has not reached the limit state and is in the elastic stage. Destructive forces act on the border of the area of bearing capacity $M_{p}$ and $N_{p}$. To determine the destructive force assume that at some stage in the calculation section acting force $M_{s}$ and $N_{s}$ (Fig. 1b).

Load the system with a unit load, due to the action of which in this section forces $M_{1}$ and $N_{1}$ will arise. Then the definitions of destructive forcescan be written as

$$
M_{p}=\frac{M_{s}+k_{1}\left(N_{0}+N_{s}\right)}{1+k_{1} / k_{0}} ; \quad N_{p}=N_{0}-\frac{M_{p}}{k_{0}},
$$

where $k_{0}=M_{0} / N_{0} ; \quad k_{1}=M_{1} / N_{1}$. 
a)

б)

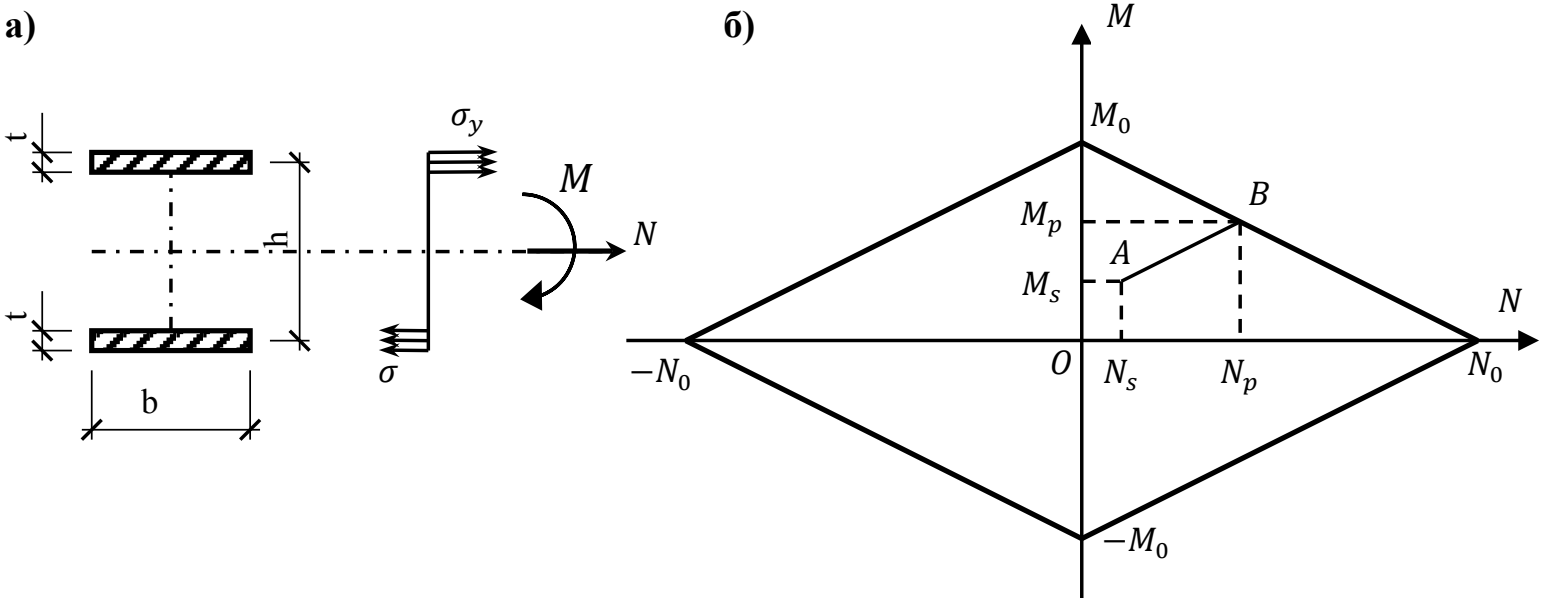

Fig. 1. Area of the bearing capacity of the idealized I-beam

For the first stage of calculation in (3) should be taken $M_{s}=N_{s}=0$.

Using this technique for finding the limit load by the example of non-hinged circular arch which is loaded with vertical load [2] (Fig. 2a). The arch has a cross section in the form of an idealized I-beam with the limit values of the moment and the longitudinal force: $\mathrm{M}_{0}=60 \mathrm{kNm} ; \mathrm{N}_{0}=120 \mathrm{kN}$. Taking the value $\mathrm{h}=1 \mathrm{~m}$,

$\sigma_{y}=245000 \mathrm{kN} / \mathrm{m}^{2}$, using (1) we find $b=0,02449 \mathrm{~m}, t=0,01 \mathrm{~m}$. Stiffness of the cross section of the $\operatorname{arch} \mathrm{EI}=3673.5 \mathrm{kMm}^{2}, \mathrm{EA}=14694 \mathrm{kN}$.

We divide the span of the arch into 6 parts and replace the curvilinear axis of the arch with a broken line, and apply the distributed load in the form of nodal forces (Fig. 2b). The diagrams of bending moments and longitudinal forces of the load $F_{0}=1$ are shown in Fig. 3c. According to the above described calculation algorithm for each arch section, it is necessary to determine $M_{p}$ and $N_{p}(3)$ and the value of the load parameter, which transfers to the section into the limit state. But in this case, based on the nature of the diagrams $M_{1}$ and $N_{1}$ (Fig. 2c), it suffices to check only the sections on the supports and the section on the axis of symmetry of the arch.

For the section on the support field we find: $M_{p}=-13.663 \mathrm{kNm}, N_{p}=-92.673 \mathrm{kN}, F=8.602 \mathrm{kN}$.

For section on the axis of symmetry: $M_{p}=24.690 \mathrm{kNm}, N_{p}=-70.620 \mathrm{kN}, F=8.976 \mathrm{kN}$.

The limit state arises in sections on the arch supports, since in this case a smaller load must be applied. Despite the fact that in the supporting sections, which are in the limit state by two bonds, the arch transformed into a mechanism. Thus, the limit load for the $\operatorname{arch} F_{0}=8.602 \mathrm{kN}$. The diagrams of forces and in the limit state of the arch are shown in fig. $2 \mathrm{~d}$.

a)

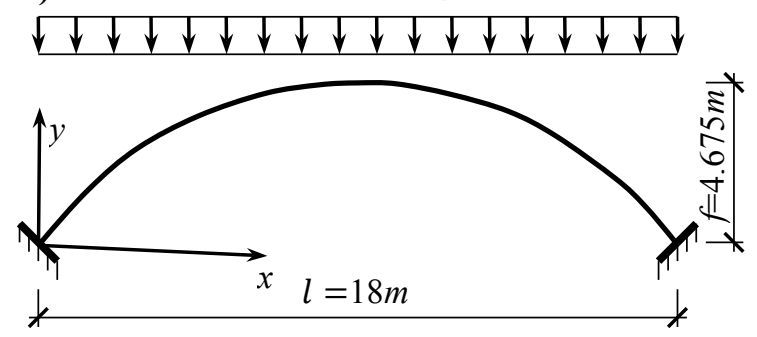

c)

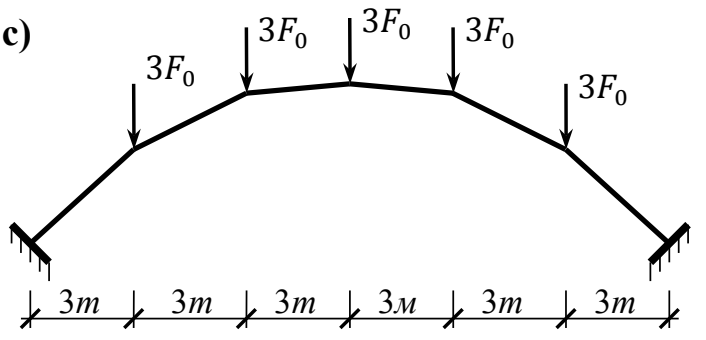

b)
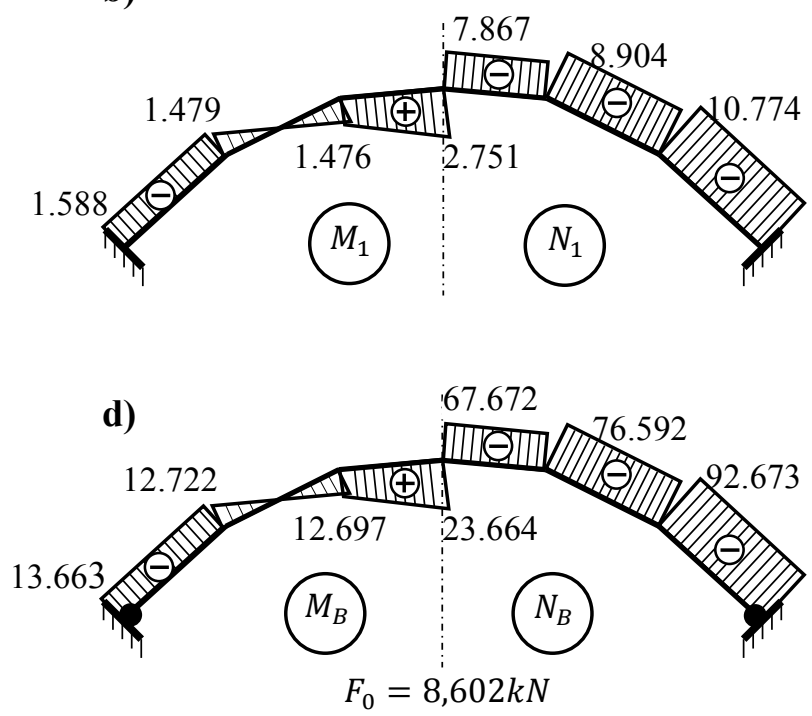

Fig. 2. Calculation of the arch by the described method 
The limit state of the arch in the case of taking into account only the bending moments is shown in Fig. 3. As we see, for the formation of the plastic mechanism of destruction it is necessary to form five plastic hinges. There is also a big difference in the parameters of the limit load.

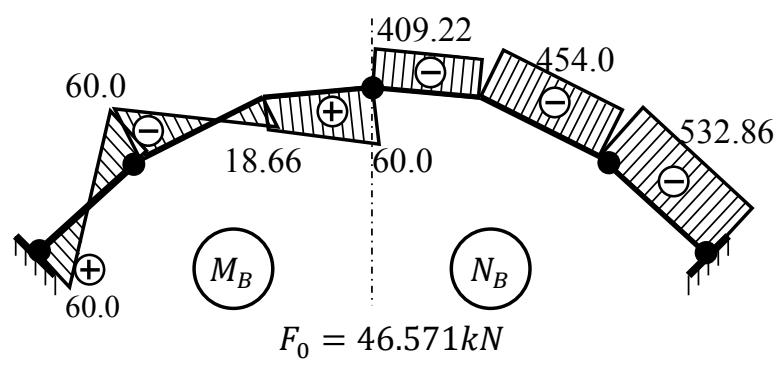

Fig. 3. The limit state of the arch calculated without taking into account the longitudinal force

Despite the fact that, when performing the calculation of a circular arch, its curvilinear axis was only divided into 6 parts and replaced with a broken line, which could lead to a loss of accuracy, it makessense to perform the calculation with a more frequent breakdown of the axis. Since manual calculation in this case seemed rather laborious, it was decided to create a calculation program on a PC. For greater versatility of the program, the finite element method was chosen as the method of static calculation. Thus, the program can perform calculations of arbitrary flat trussed systems including variable stiffness. The choice of a high level programming language $\mathrm{C}++$ made it possible to obtain a fast and compact calculation module.

Using the compiled program calculated the arch shown in Fig. 2a, with an axis split into 134 parts. The following results were obtained: the limit state arose in two sections - at a distance of $x=1,075 \mathrm{~m}$, from the arch supports; the limit load is $7.923 \mathrm{kN} / \mathrm{m}$. As we can see, the magnitude of the limit load and the position of the sections where the limit state occurs, largely depends on the breakdown of the arch axis. To control the correctness of the compiled program for calculating the non-hinged circular arch (Fig. 2a), it was also calculated analytically. The calculation was performed in the polar coordinate system (Fig. 4a).

To move from the Cartesian coordinate system to the polar coordinate system, the dependencies are used: $x=R \cos \alpha ; y=R \sin \alpha-y_{0} ; d s=R d \alpha$.

The radius of the circle $R$ and the distance from the center of the circle to the center of the elastic weight of the arch $y_{0}$ are determined by the formulas

$$
R=\frac{f}{2}+\frac{l^{2}}{8 f} ; \quad y_{0}=R \frac{\sin \left(0.5\left(\alpha_{k}-\alpha_{0}\right)\right)}{0.5\left(\alpha_{k}-\alpha_{0}\right)},
$$

where $\alpha_{0}=\tan ^{-1} \frac{R-f}{l / 2} ; \quad \alpha_{k}=\pi-\alpha_{0}$.

a)

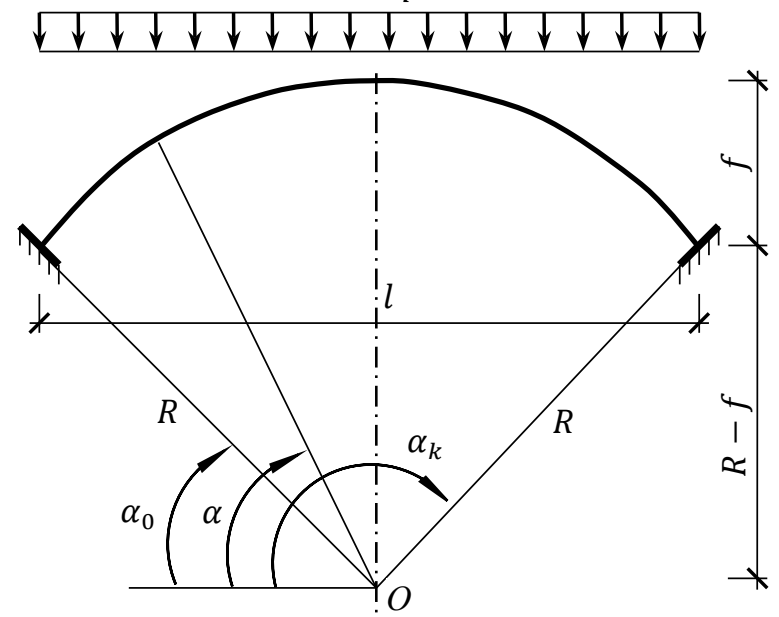

b)

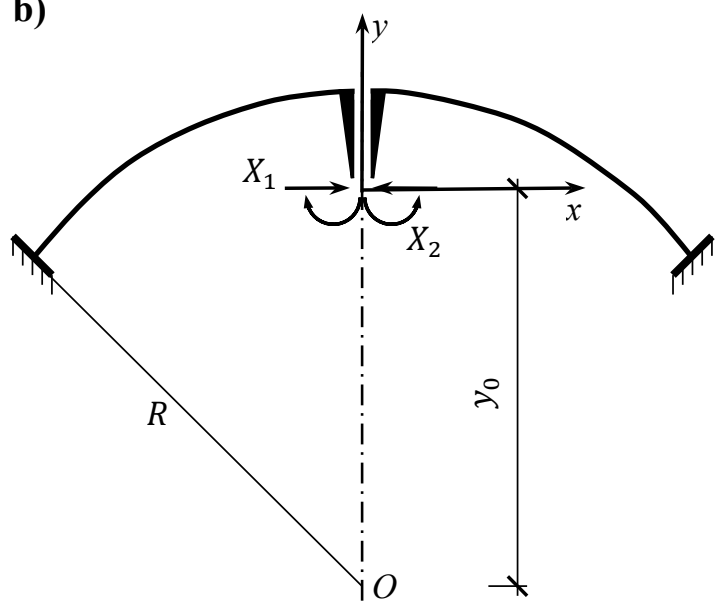

Fig. 4. a) scheme of the arch; b) the basic system of the method of forces 
The calculation of the arch is performed by the method of forces. Since the load is symmetrical, only two unknown of the methods of forces remain (Fig. 4b). For the adopted main system of the method of forces, canonical equations are written as

$$
\begin{aligned}
& \delta_{11} X_{1}+\Delta_{1 q}=0 \\
& \delta_{22} X_{2}+\Delta_{2 q}=0 .
\end{aligned}
$$

Unit and cargo diagrams of moments and longitudinal forces in the main system are described by dependencies:

$$
\begin{aligned}
\bar{M}_{1} & =-y=y_{0}-R \sin \alpha ; \bar{M}_{2}=-1 ; \\
\bar{N}_{1} & =-\sin \alpha ; \bar{N}_{2}=0 ; \\
M_{q}^{0} & =-\frac{q x^{2}}{2}=-\frac{q R^{2}}{2} \cos ^{2} \alpha ; N_{q}^{0}=-q x \cos \alpha=-q R \cos ^{2} \alpha .
\end{aligned}
$$

The coefficients of the system of canonical equations of the method of forces were determined by the Mohr formula with allowance for bending moments and longitudinal forces:

$$
\begin{aligned}
& \delta_{11}=\frac{2}{E I} \int_{\alpha_{0}}^{\pi / 2}\left(\bar{M}_{1}\right)^{2} R d \alpha+\frac{2}{E A} \int_{\alpha_{0}}^{\pi / 2}\left(\bar{N}_{1}\right)^{2} R d \alpha= \\
& =\frac{2 R}{E I}\left[\left(y_{0}^{2}+\frac{R^{2}}{2}\right)\left(\frac{\pi}{2}-\alpha_{0}\right)-2 R y_{0} \cos \alpha_{0}+\frac{R^{2}}{4} \sin 2 \alpha_{0}\right]+\frac{R}{E A}\left(\frac{\pi}{2}-\alpha_{0}+0.5 \sin 2 \alpha_{0}\right) ; \\
& \delta_{22}=\frac{2}{E I} \int_{\alpha_{0}}^{\pi / 2}\left(\bar{M}_{2}\right)^{2} R d \alpha+\frac{2}{E A} \int_{\alpha_{0}}^{\pi / 2}\left(\bar{N}_{2}\right)^{2} R d \alpha=\frac{2 R}{E I}\left(\frac{\pi}{2}-\alpha_{0}\right) ; \\
& \Delta_{1 q}=\frac{2}{E I} \int_{\alpha_{0}}^{\pi / 2} \bar{M}_{1} M_{q}^{0} R d \alpha+\frac{2}{E A} \int_{\alpha_{0}}^{\pi / 2} \bar{N}_{1} N_{q}^{0} R d \alpha=-\frac{q R^{3}}{E I}\left[\frac{y_{0}}{2}\left(\frac{\pi}{2}-\alpha_{0}\right)-\frac{y_{0}}{4} \sin 2 \alpha_{0}-\frac{R}{3} \cos ^{3} \alpha_{0}\right]+\frac{2 q R^{2}}{3 E A} \cos ^{3} \alpha_{0} \\
& \Delta_{2 q}=\frac{2}{E I} \int_{\alpha_{0}}^{\pi / 2} \bar{M}_{2} M_{q}^{0} R d \alpha+\frac{2}{E A} \int_{\alpha_{0}}^{\pi / 2} \bar{N}_{2} N_{q}^{0} R d \alpha==\frac{q R^{3}}{2 E I}\left(\frac{\pi}{2}-\alpha_{0}-0.5 \sin 2 \alpha_{0}\right) .
\end{aligned}
$$

Having calculated the values of the unknowns from the canonical equations of the method of forces, we obtain the dependences

$$
X_{1}=-\Delta_{1 q} / \delta_{11}=H ; \quad X_{2}=-\Delta_{2 q} / \delta_{22}=M_{C},
$$

where $H$ - arch thrust; $M_{C}$ - the bending moment on the axis of symmetry of the arch, write expressions to determine the moments and longitudinal forces in the sections of the arch:

$$
\begin{aligned}
& M=M_{q}^{0}+\bar{M}_{1} H+\bar{M}_{2} M_{C}=-\frac{q R^{2}}{2} \cos ^{2} \alpha+H\left(y_{0}-R \sin \alpha\right)-M_{C} ; \\
& N=N_{q}^{0}+\bar{N}_{1} H=-q R \cos ^{2} \alpha-H \sin \alpha .
\end{aligned}
$$

In the case of a vertical uniformly distributed load, the limit state may occur in the support sections (on the axis of symmetry and in the most intense sections between supports and the axis of symmetry). To identify the most intense sections of the arch, we write down the expression for determining stresses and equate the derivative of stresses to zero

$$
\sigma=\frac{N}{A} \pm \frac{M}{W}
$$

where $A=2 b t$ - cross-section area; $W=b t h$ - resistancemoment of the cross section.

$$
\begin{aligned}
& \sigma=-q R\left(\frac{1}{A} \pm \frac{R}{2 W}\right) \cos ^{2} \alpha-H\left(\frac{1}{A} \pm \frac{R}{W}\right) \sin \alpha \pm \frac{H y_{0}}{W} \mp \frac{M_{C}}{W} . \\
& \frac{d \sigma}{d \alpha}=\left[2 q R\left(\frac{1}{A} \pm \frac{R}{2 W}\right) \sin \alpha-H\left(\frac{1}{A} \pm \frac{R}{W}\right)\right] \cos \alpha=0 .
\end{aligned}
$$


The last equation has two solutions:

a) $\cos \alpha=0$, then $\alpha=\pi / 2$ and the maximum stress occurs on the axis of symmetry of the arch;

b) the expression in square brackets is zero, then the coordinate with the maximum stress is determined from the expression:

$$
\sin \alpha_{m}=\frac{H}{q R} \frac{W \pm A R}{2 W \pm A R} .
$$

Using the obtained dependencies, the numerical calculation of the arch can be performed by the following algorithm:

- calculates the value of displacements and unknown forces method $(7,8)$ from the load parameter $q=1$;

-for three cross sections, in which limit state $\left(\alpha=\alpha_{0}, \alpha=\alpha_{m}, \alpha=\pi / 2\right)$ can occur, the values of the moment and the longitudinal force (9) are calculated, and the stress is determined $\sigma_{1}(10)$;

- for each section, the loads were determined, which leads to plastic deformations in this section $(q=$ $\left.\sigma_{y} /\left|\sigma_{1}\right|\right)$

- in the section for which the smallest load value was determined, a limit state occurs.

If the limit state occurs in sections with coordinates, $\alpha=\alpha_{0}$, or $\alpha=\alpha_{m}$ (and, therefore, in symmetric sections on the right side of the arch), it is enough for the arch to become a mechanism and the calculated load will be the ultimate. If the limit state occurs in a section located on the axis of symmetry of the arch, the limit state of the arch will not be reached.To determine the limit load the arch design scheme must be changed and loaded to final value.

For the arch, which is considered (Fig. 2a), the following load values are defined:

- for $\alpha=\alpha_{0}, \quad q=9.0468 \mathrm{kN} / \mathrm{m}$;

- for $\alpha=\alpha_{m}=0.7672$ рад, $q=7.9270 \mathrm{kN} / \mathrm{m}$;

- for $\alpha=\pi / 2, q=9.1274 \mathrm{kN} / \mathrm{m}$.

Thus, the parameter of limit load for a given arch is equal $q_{0}=7.9270 \mathrm{kN} / \mathrm{m}$ and the limit state occurs in sections at a distance of $1.0814 \mathrm{~m}$ from the arch supports. The diagram of effort $M$ and $N$ in the limit state of the arch are shown in Fig. 5.

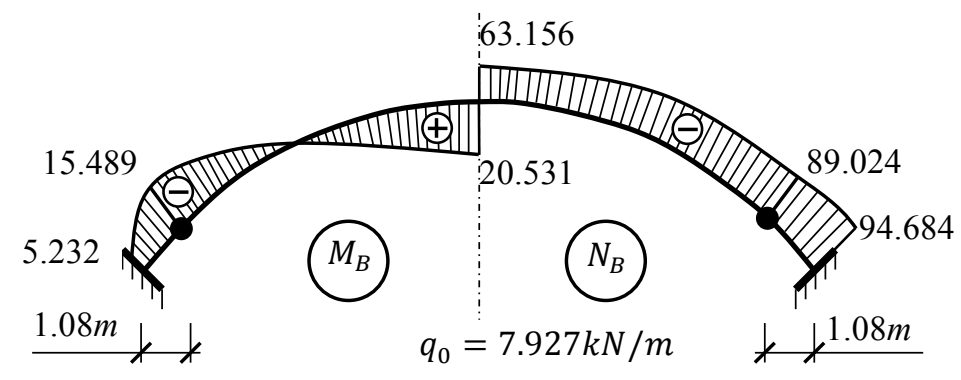

Fig. 5. The limit state of the arch (analytical solution)

Comparison of the limit load obtained from the compiled program using the described algorithm $\left(q_{0}=\right.$ $7.923 \mathrm{kN} / \mathrm{m})$ and analytical method $\left(q_{0}=7.927 \mathrm{kN} / \mathrm{m}\right)$ shows fairly accurate results. The calculation error is $0.05 \%$. The coordinate of the section where the limit state occurs $(1.075 \mathrm{~m}$ calculated by the program and $1.0814 m$ calculated analytically) differ by $0.59 \%$.

If the curvilinear axis of the arch is replaced by a broken line of six segments (Fig. 3), then the value of the limit load $\left(q_{0}=8.602 \mathrm{kN} / \mathrm{m}\right)$ is greater than that obtained analytically by $8.52 \%$ and plastic deformations arise in sections on the arch supports. 


\section{CONCLUSION}

1. The direct calculation method [7] can be quite effectively used to calculate the limit state of structures with regard to the bending moment and the longitudinal force.

2. To obtain reliable results with numerous calculations of the arch, its axis should be divided into a sufficient number of straight line segments.

3. The calculation of the bearing capacity of the arch without considering the longitudinal force leads to a significant overestimation of the limit load.

4. For the formation of a plastic mechanism of destruction, taking into account the longitudinal force, the formation of a limit state ina much smaller number of sections than without considering the longitudinal force is necessary.

5. The proposed calculation method can be used to calculate the limit load of trussed systems with any crosssectional shape.

\section{REFERENCES}

[1] GvozdevA.A. Raschetn esuschejs posobnosti konstrykcij po metody predelnogo ravnovesiya. Moscow: Stroyizdat, (1949), - 248 p. (in Russian)

[2] Rzhanitsyn A.R. Raschet soorygenij s ychetom plasticheskih svoistv materialov. Moscow: The state publishing house of literature on construction and architecture, (1954), $287 \mathrm{p}$

[3] Pikovsky A.A. Statikasterzhnevih system so szhatimy elementamy. Moscow: State publishing house of physical and mathematical literature, (1961), 394 p. (in Russian)

[4] Chiras A.A. Stroitelnaya mekhanika, teorija I algoritmi. Moscow: Stroyizdat, (1989), 256 p.

[5] Popov N.I. O predelnom sostoyanii arki, nagrygenoj sistemoj sosredotochennih sil Works RIIZhT, the issue 29, 1961.

[6] Chan Tkhan Tung. Chislennij method raschet arok po predelnomy ravnovesiu. Moscow: MGSU bulletin, 2011, No. 1, t. 1, page $232-$ 237 (in Russian)

[7] Darkov A.V., Shaposhnikov N.N. Stroitelnaya mechanika Moscow: "Higher school", (1986), 607 p. (in Russian)

[8] Soroka M.M. Rozvyazok nelineinih zadach budivelno yimekhanicki: navch. pos. / M.M. Soroka - Odessa: ODABA, (2018). - 203 p. (in Ukrainian)

[9] Barabash M.S., Soroka M.M., Suryaninov M.G.Nelineina budivelna mekhanika z PK LIRA-SAPR.monografiya, Odessa: Ekologiya, 2018. - 248 p, (in Ukrainian) 